\title{
Attenuation of Lead-Induced Neurotoxicity by Omega-3 Fatty Acid in Rats
}

\author{
Pramod Kumar Singh ${ }^{a}$ Manish Kumar Singh ${ }^{b}$ Rajesh Singh Yadav ${ }^{c}$ \\ Rakesh Kumar Dixit ${ }^{a}$ Anju Mehrotra ${ }^{a}$ Rajendra Nath ${ }^{a}$ \\ aDepartment of Pharmacology and Therapeutics, King George's Medical University, Lucknow, India; \\ ${ }^{b}$ Department of Biochemistry, Moti Lal Nehru Medical College, Allahabad, India; ' Department of \\ Criminology and Forensic Science, Dr. Harisingh Gour Central University, Sagar, India
}

\section{Keywords}

Lead $\cdot$ Neurotoxicity $\cdot$ Omega-3 fatty acid $\cdot$ Rats .

Neuroprotection

\begin{abstract}
Background: Lead is widely distributed in the environment and has been found to be associated with various health problems including neurodegenerative diseases. Purpose: In view of the increasing health risk caused by lead, this study has been carried out to investigate the neuroprotective effect of omega-3 fatty acid (omega-3FA) in lead-induced neurotoxicity in rats. Methods: Biochemical parameters including oxidative stress in brain regions, lead levels in blood and brain regions and histopathological examination of brain regions of rats were carried out in the present study. Results: Rats exposed to lead (lead acetate $7.5 \mathrm{mg} / \mathrm{kg}$ body weight p.o. for 14 days) caused a significant increase in the levels of lipid peroxidation, protein carbonyl content, ROS production and decreased the activities of glutathione peroxidase, superoxide dismutase and catalase in the cerebellum and cerebral cortex, respectively, as compared to controls. Abnormal histopathological changes and increase in the levels of lead in blood and brain were also observed as compared to controls. Co-treatment of lead with omega-3FA (750 mg/ $\mathrm{kg}$ body weight p.o. for 14 days) decreased the levels of lipid
\end{abstract}

peroxidation, protein carbonyl content, ROS production and increased the activities of glutathione peroxidase, superoxide dismutase and catalase and showed protection in the histopathological study as compared to rats treated with lead alone. Conclusions: The result of the present study shows that lead-induced oxidative stress and histopathological alteration in the brain region were significantly protected with co-treatment of lead and omega-3FA. This could be due to its strong antioxidant potential and metal-binding property.

(c) 2017 S. Karger AG, Basel

\section{Introduction}

Lead is a ubiquitous heavy metal that exists in the environment due to its natural origin and as a result of industrial uses. It causes insidious hazard with potential adverse health effects and brain-related disorders and diseases $[1,2]$. Exposure to lead in humans mainly occurs through petroleum products, leaded paints and drinking water, which all result in cardiovascular, renal, immune, bone and neurological disorders [3-5]. Notably, the developing nervous system is more vulnerable to the toxicity of lead; therefore, children are at a higher risk to be affected by its toxicity [6]. Occupational exposure to lead 
among industrial workers leads to the accumulation of this heavy metal in their body organs and tissues [7]. Experimental studies suggested that cholinergic dysfunction, glutamate receptor alteration and enhanced oxidative stress were all associated with lead-induced neurotoxicity $[8,9]$.

Epidemiological studies have revealed that chronic poisoning of lead may cause CNS injury in young children and also affects their growth, decreased intelligence, short-term memory, hearing loss, permanent brain damage and even death [10]. Studies have also reported that exposure to lead even at a low level may cause peripheral artery disease, hypertension, renal problems, neurodegeneration and cognitive impairment and behavioural dysfunctions [11]. High lead exposure among occupational workers has been reported to be associated with enhanced generation of free radical species leading to oxidative damage and depletion of antioxidant defence system in the individuals $[12,13]$. Peripheral neuropathy has also been observed in lead neurotoxicity that further cause reduced motor activity due to loss of myelin sheath and thus impaired the signal transmission between nerves, causing muscular weakness, especially of the exterior muscles, fatigue and lack of muscular coordination [14].

Metal chelating agents and natural antioxidants have been used to explore their beneficial effects in lead-induced neurotoxicity $[9,15,16]$. The increasing evidences support the beneficial effect of an increased intake of omega-3 fatty acids (omega-3FA) in a variety of neurodegenerative and neurological conditions [17]. The dietary sources of omega-3FA are fish and sea foods, which are rich sources of DHA. The role of omega-3FA especially DHA in brain development is gaining widespread attention [18]. DHA, which is the core member of omega-3FA, is highly concentrated in the brain and the outer segments of retinal rods and cones, constituting around $50 \%$ of the total polyunsaturated fatty acids [19]. Numerous studies have reported that maternal supplementation of DHA during gestation has neuroprotective effects against prenatal stress-induced brain dysfunction, hyperoxic injury and hypoxic ischemic injury $[20,21]$. Several evidences from animal and human studies have shown a positive association between DHA and cognitive development [22]. Recently, Rathod et al. [23] reported that the role of omega-3FA in influencing brain health and well-being. In our earlier studies, we have reported that omega-3FA significantly reduced the lead-induced oxidative stress and lead levels in blood and brain associated with brain damage in a long-term exposure study (90 days). The results were similar to that of standard drug, vitamin E [15]. In another study, we have also reported that lead-induced impairment in neurotransmitters levels linked with motor activity, grip strength and learning and memory performance in wistar rats significantly corrected following co-treatment with lead and omega-3FA in the cerebral cortex and cerebellum of brain for 14 days of treatment [16]. In continuation to this study, the present study has been carried out to explore the neuroprotective efficacy of omega-3FA in lead-induced neurotoxicity in cerebral cortex and cerebellum of rats.

\section{Methods}

\section{Chemicals}

Lead acetate $\left(\left[\mathrm{C}_{2} \mathrm{H}_{3} \mathrm{O}_{2}\right]_{2} \mathrm{~Pb} .3 \mathrm{H}_{2} \mathrm{O}\right)$, nicotinamide adenine dinucleotide, 5,5-dithiobis 2-nitrobenzoic acid, trichloro acetic acid, reduced glutathione $(\mathrm{GSH})$, sodium chloride $(\mathrm{NaCl})$, potassium chloride $(\mathrm{KCl})$, disodium hydrogen phosphate $\left(\mathrm{Na}_{2} \mathrm{HPO}_{4}\right)$, potassium ortho phosphate $\left(\mathrm{H}_{2} \mathrm{KO}_{4} \mathrm{P}\right)$, hydrochloric acid $(\mathrm{HCl})$, nitric acid $\left(\mathrm{HNO}_{3}\right), 2,7$ dichlorodihydro fluorescein diacetate, ethylene diaminetetraacetate (EDTA), hydrogen peroxide $\left(\mathrm{H}_{2} \mathrm{O}_{2}\right)$ and perchloric acid $\left(\mathrm{HClO}_{4}\right)$ were purchased from Sigma-Aldrich and omega-3FA (DHA + EPA) suspension from fish lipid oil was purchased from Merck Pharmaceuticals Ltd.

\section{Animals and Treatment}

Male Wistar rats $(n=24)$ of approximately same weight (180 \pm $20 \mathrm{~g}$ ) were purchased from the animal house of CSIR-Indian Institute of Toxicology Research, Lucknow (UP), India and acclimatized for 1 week before experimental use. The animals were separately housed in polypropylene cages at room temperature of $22 \pm$ $2{ }^{\circ} \mathrm{C}$, relative humidity of $50 \pm 10 \%$ and 12 -h light dark cycles. They were allowed to have free access to pellet diet and water ad libitum. The study was approved by the Institutional Animal Ethics Committee (34/IAH/Pharma-12) of King George's Medical University, Lucknow, India and all experiments were carried out within the guidelines of the committee for the purpose of control and supervision of experiments on animals, Ministry of Environment and Forests (Government of India), New Delhi, India.

Rats were randomly divided into four groups (control and experimental groups) and simultaneous treatment was given to all 6 animals in each group as follows:

Group I: rats were treated with distilled water (vehicle), which serves as control for 14 days.

Group II: rats were treated with lead acetate $(7.5 \mathrm{mg} / \mathrm{kg}$ b.w.t./ oral) for 14 days.

Group III: rats were treated with omega-3FA $(750 \mathrm{mg} / \mathrm{kg}$ b.w t./oral) for 14 days.

Group IV: rats were treated with lead acetate and omega-3FA in combination identically as in groups II and III for 14 days.

Blood Collection and Tissue Homogenate Preparation

After the last dose of treatment, rats were made to fast for $12 \mathrm{~h}$ before being anesthetized by injection (intraperitonial) of sodium pentothal solution $(50 \mathrm{mg} / \mathrm{kg}$ b.w.t.). Blood sample was withdrawn 
through retro-orbital plexus and collected in EDTA-coated glass tubes for estimation of blood lead levels. Five rats from each treatment group were sacrificed by cervical decapitation and brains were immediately excised, cleaned, weighed and dissected into the cerebellum and cerebral cortex according to the method suggested by Glowinski and Iversen [24]. Both cerebellum and cerebral cortex were processed for the analysis of biochemical assays. For the histopathological studies, whole brain from each group were perfused with the help of $4 \%$ paraformaldehyde and used for the study. The brain regions were homogenized in a phosphate-buffered solution and used for the biochemical analysis after suitable sample preparation.

\section{Biochemical Parameters}

\section{Measurement of Reactive Oxygen Species}

ROS levels in the brain region were performed according to the method of Socci et al. [25] with few modifications by using 2,7-dichlorofluorescin diacetate that is converted into highly fluorescent 2,7-dichlorofluorescin by hydrogen peroxide. Fluorescence was determined at $488-\mathrm{nm}$ excitation and $525-\mathrm{nm}$ emission of wavelengths using a fluorescence plate reader. The amount of ROS level was expressed as $\mathrm{nmol} / \mathrm{min} / \mathrm{mg}$ protein.

\section{Assay of Lipid Peroxidation}

Lipid peroxidation was analyzed as a measurement of thiobarbituric acid reactive substances (TBARS) by using the standard protocol [26]. The reaction mixture in a final volume of $3.0 \mathrm{~mL}$ contained the tissue homogenate $(0.1 \mathrm{~mL}), 500 \mu \mathrm{L}$ of $8 \%$ SDS, 500 $\mu \mathrm{L}$ of $20 \%$ glacial acetic acid and $1.5 \mathrm{~mL}$ of $0.8 \%$ TBA. The mixture was placed in a boiling water bath for $1 \mathrm{~h}$ at $100^{\circ} \mathrm{C}$ and immediately shifted to crushed ice bath for $10 \mathrm{~min}$. The mixture was centrifuged at 2,500 $\mathrm{g}$ for $10 \mathrm{~min}$. The intensity of pink color formed during the reaction was read at $532 \mathrm{~nm}$. The amount of TBARS during the reaction was calculated using a molar extinction coefficient of $1.56 \times 105 \mathrm{M} \mathrm{cm}^{-1}$.

\section{Assay of Protein Carbonyl Content}

Protein carbonyl content was measured by the method suggested by Levine et al. [27] using 2,4-dinitrophenylhydrazine as a substrate. The optical density was read on spectrophotometer at $375 \mathrm{~nm}$ and the amount of carbonyl content (C) was calculated using a molar extinction coefficient $(\varepsilon)$ of $22.0 \mathrm{~mm}^{-1} \mathrm{~cm}^{-1}$ for aliphatic hydrazones.

\section{Assay of Superoxide Dismutase Activity}

The activity of SOD in brain regions was assayed by the method suggested by McCord and Fridovich [28]. The assays were carried out in 2 sets; to the first set $0.2 \mathrm{~mL}$ Nitro blue tetrazolium, 0.2 $\mathrm{mL}$ phenazinemethosulphate, $1.8 \mathrm{~mL}$ sodium pyrophosphate buffer and $0.1 \mathrm{~mL}$ enzyme source were added. To the second set, all the above reagents except the sample were added. The reaction was started simultaneously by adding $0.2 \mathrm{~mL}$ nicotinamide adenine dinucleotide. After an interval of $90 \mathrm{~s}, 0.5 \mathrm{~mL}$ glacial acetic acid was added to each tube for checking the reaction. The absorbance was read at $560 \mathrm{~nm}$ against the blank. Net change in OD that corresponds to amount of reduction of nitro blue tetrazolium was considered to calculate the SOD activity, which was expressed as units/ $\mathrm{min} / \mathrm{mg}$ protein.

Attenuation of Lead-Induced

Neurotoxicity by Omega-3FA in Rats
Assay of Catalase Activity

Catalase activity was assayed following the method of Aebi [29], using $\mathrm{H}_{2} \mathrm{O}_{2}$ as the substrate. The decrease in absorbance at $240 \mathrm{~nm}$ was recorded after every $30 \mathrm{~s}$ for $2.5 \mathrm{~min}$. The activity of the enzyme was calculated using the molar extinction coefficient $43.6 \mathrm{M} \mathrm{cm}^{-1}$ and values are expressed in units $/ \mathrm{min} / \mathrm{mg}$ protein.

\section{Assay of Glutathione Peroxidase Activity}

GPx activity was measured by the procedure of Pagila and Valentine [30]. The reaction mixture consisting of $50 \mathrm{mM}$ potassium phosphate buffer, EDTA (1 mM), $\mathrm{NaN}_{3}$ (1 mM), NADPH $(0.2$ $\mathrm{mM})$, GSSG-R (1 unit), GSH (1 mM) was set in a total volume of $2.5 \mathrm{~mL}$. Samples were added to the above mixture and allowed to incubate for $5 \mathrm{~min}$ at room temperature. The reaction was initiated by adding $\mathrm{H}_{2} \mathrm{O}_{2}(0.25 \mathrm{~mm})$. Optical density at $340 \mathrm{~nm}$ was recorded for 3 min after every 30 -s interval. The enzyme activity was expressed as $\mu \mathrm{mol} / \mathrm{min} / \mathrm{mg}$ protein.

\section{Protein Estimation}

Protein content was assayed by the method suggested by Lowry et al. [31], using serum albumin (bovine) as a reference standard.

\section{Estimation of Lead Content in Blood and Brain Regions}

Lead levels in blood and brain regions (cerebellum and cerebral cortex) were estimated as described by Gupta and Gill [32]. The optical density was read at $283 \mathrm{~nm}$ by using the graphite furnace atomic absorption spectrophotometer. A calibration curve was constructed by adding known amounts of lead standard to calculate lead levels in the blood and brain tissue and data were expressed as $\mu \mathrm{g} / \mathrm{dL}$ blood or $\mu \mathrm{g} / \mathrm{g}$ wet tissue.

\section{Histopathological Studies}

Brain regions (cerebellum and cerebral cortex) from different animal groups were fixed at $10 \%$ neutral buffered formalin for the histopathological examination. After proper fixation, the brain tissue was rinsed with water and dehydrated in ascending order of alcohols (30, 50, 70, 90, and 100\%) and then cleaned in xylene. Paraffin blocks were prepared and cut into $2-4 \mu$ thin sections. Sections were stained with haematoxylin and eosin, cleaned in xylene, mounted in DPX and examined under light microscope for interpretation.

\section{Statistical Analysis}

Data has been expressed as the mean \pm SE. The statistical analysis was carried out by GraphPad Prism 5.01 using one-way analysis of variance followed by Newman-Keuls test for multiple pairwise comparisons among the groups. Values up to $p<0.05$ have been considered significant.

\section{Results}

\section{Effect on Body and Brain Weight}

Oral administration of lead acetate in rats for 14 days resulted in a decrease in the body weight (13\%) and no significant changes were found in brain weight as compared to controls. Co-treatment with lead and omega3FA in rats caused no significant changes in body 
Fig. 1. Effect of lead, omega-3 fatty acid (omega-3FA) and their co-treatment on the generation of reactive oxygen species in brain regions of rats. Values are mean \pm SE $(n=5) .{ }^{* * \text {, a }} p<0.01$-compared to those in the control group, ${ }^{*, \mathrm{~b}} p<0.05$ compared to the values in the lead-treated group.

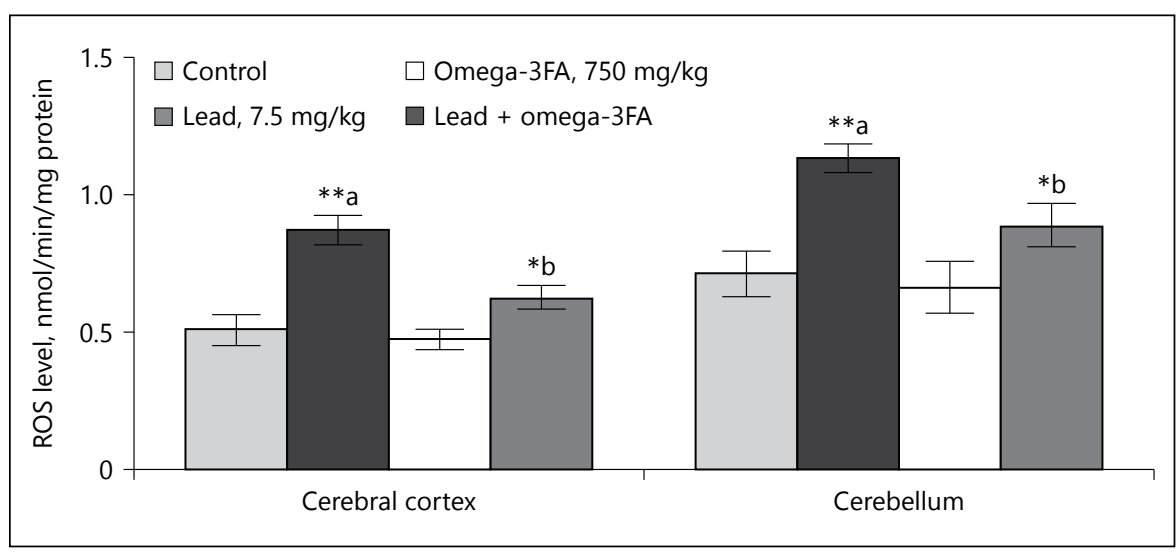

Table 1. Effect of lead, omega-3FA and their co-treatment on body and brain weight of rats

\begin{tabular}{lll}
\hline Group & Body weight, g & Brain weight, g \\
\hline Control & $220 \pm 5.7$ & $1.71 \pm 0.04$ \\
Lead $(7.5 \mathrm{mg} / \mathrm{kg})$ & $190 \pm 5.24^{\mathrm{a}, *}$ & $1.63 \pm 0.05^{\mathrm{ns}}$ \\
Omega-3FA $(750 \mathrm{mg} / \mathrm{kg})$ & $210 \pm 6.12$ & $1.67 \pm 0.03^{\mathrm{ns}}$ \\
Lead + omega-3FA & $198 \pm 6.04^{\mathrm{a}, *}$ & $1.69 \pm 0.04^{\mathrm{ns}}$ \\
\hline
\end{tabular}

All values are mean $\pm \operatorname{SE}(n=5)$. ${ }^{a} *$ $p<0.05$ compared to control group; ns, non significant.

weight and brain weight as compared to rats treated with lead alone (Table 1). No significant changes in body weight and brain weight were observed in rats treated with omega-3FA alone as compared to control (Table 1).

\section{Effect on the Reactive Oxygen Species Level}

To assess the level of oxidative damage to the biological membrane, the effect of lead and co-treatment of lead and omega-3FA on reactive oxygen species in cerebral cortex and cerebellum of brain have been carried out and presented in Figure 1. The levels of ROS were significantly increased in cerebral cortex (72\%) and cerebellum (59\%) of rats treated with lead when compared to controls. Cotreatment with lead and omega-3FA in rats caused a decrease in the ROS level in cerebral cortex (27\%) and cerebellum (22\%) in comparison to rats treated with lead alone. No significant change in the ROS levels was observed in brain regions of rats treated with omega-3FA alone when compared to rats in the control group (Fig. 1).

\section{Effect on Lipid Peroxidation and Protein Carbonyl \\ Contents}

A significant increased level of TBARS and protein carbonyl content in cerebral cortex $(58 \%, 72 \%)$ and cer- ebellum $(52 \%, 75 \%)$ were observed in rats treated with lead as compared to control (Fig. 2, 3). Co-treatment with lead and omega-3FA in rats caused a significant decrease in TBARS and protein carbonyl contents in cerebral cortex $(23 \%, 31 \%)$ and cerebellum $(25 \%, 23 \%)$ as compared to rats treated with lead alone (Fig. 2, 3). No significant change in both TBARS and protein carbonyl contents was observed in brain regions of rats treated with omega-3FA alone as compared to controls (Fig. 2, 3).

\section{Effect on Superoxide Dismutase and Catalase Activities}

The activity of SOD and catalase was significantly decreased in cerebral cortex $(38 \%, 44 \%)$ and cerebellum $(23 \%, 42 \%)$ of lead-treated rats as compared to ontrols (Fig. 4, 5). Co-treatment with lead and omega-3FA was found to significantly increase the activity of SOD and catalase in the cerebral cortex $(35 \%, 51 \%)$ and cerebellum $(15 \%, 44 \%)$ when compared to rats treated with lead alone. No significant change in both SOD and catalase activity was observed in brain regions of the rats treated with omega-3FA alone as compared to controls (Fig. 4, $5)$. 
Fig. 2. Effect of lead, omega-3 fatty acid (omega-3FA) and their co-treatment on the levels of lipid peroxidation in brain regions of rats. Values are mean $\pm \operatorname{SE}(n=5)$. ${ }^{*}$, a $p<0.05,{ }^{* *}$, a $p<0.01$-compared to values in the control group, ${ }^{*, b} p<0.05$-compared to values in the lead-treated group.

Fig. 3. Effect of lead, omega-3 fatty acid (omega-3FA) and their co-treatment on the levels of protein carbonyl contents in brain regions of rats. Values are mean $\pm \mathrm{SE}$ $(n=5) .{ }^{* *, a} p<0.01$-compared to values in the control group, ${ }^{*}, \mathrm{~b} p<0.05,{ }^{* *}, \mathrm{~b} p<$ 0.01 -compared to values in the lead-treated group.

Fig. 4. Effect of lead, omega-3 fatty acid (omega-3FA) and their co-treatment on the activity of superoxide dismutase in brain regions of rats. Values are mean $\pm \mathrm{SE}$ $(n=5) .{ }^{*}$, a $p<0.05$-compared to values in the control group, ${ }^{*}$ b $p<0.05$-compared to values in the lead-treated group.
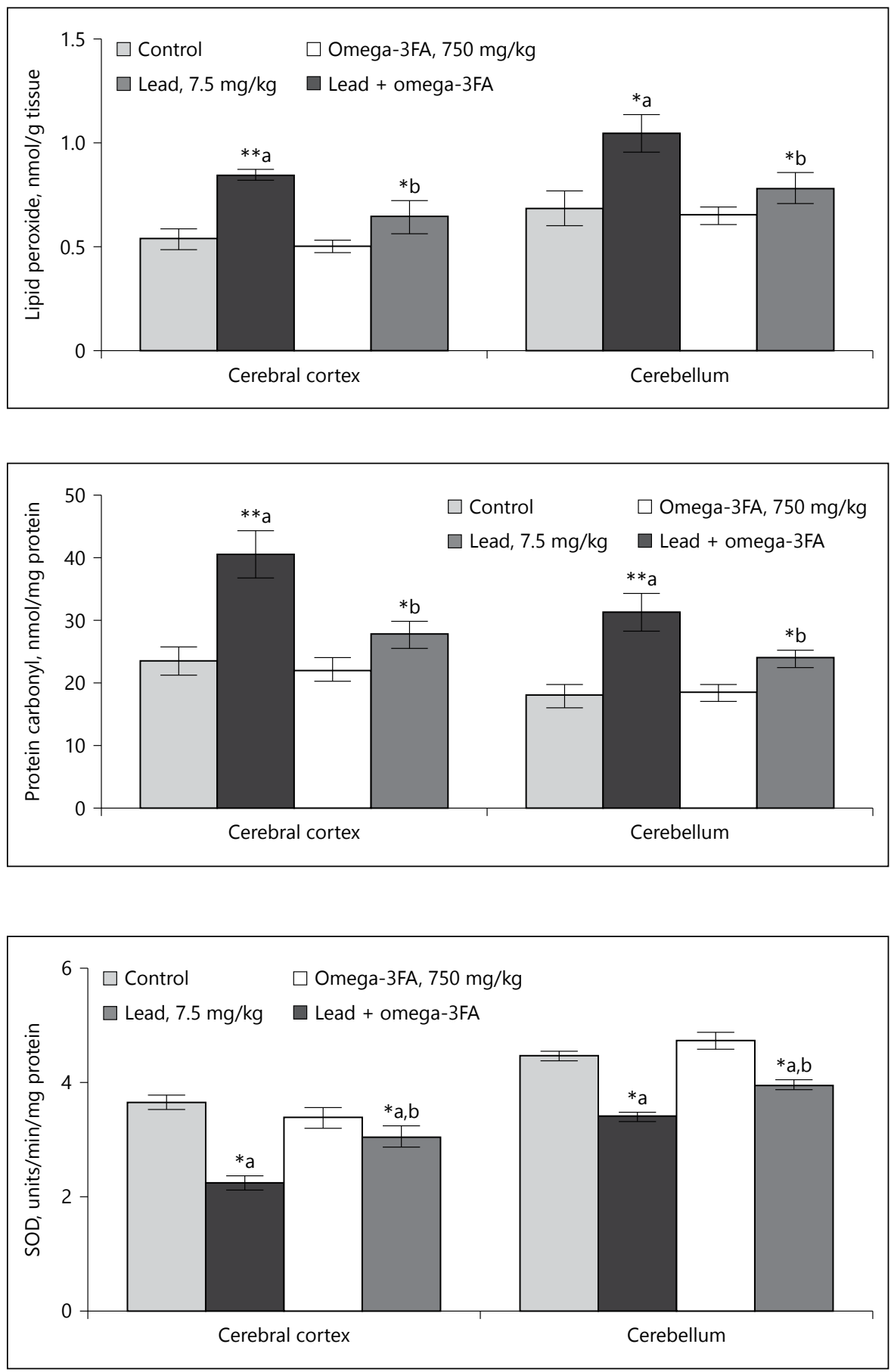

\section{Effect on Glutathione Peroxidase Activity}

A significant decrease in GPx activity in cerebral cortex $(29 \%)$ and cerebellum (36\%) of rats were observed in the lead-treated group as compared to controls. Co-treatment with lead and omega-3FA was found to significantly increase the activity of GPx in cerebral cortex (36\%) and cerebellum (31\%) when compared to rats treated with lead alone. No significant changes in the GPx activity were observed in brain regions of rats treated with omega-3F alone as compared to controls (Fig. 6).

\section{Effect on Lead Levels in Blood and Brain Regions}

The levels of lead were significantly increased in cerebral cortex ( 1.7 fold), cerebellum (1.8 fold) and in blood 
Fig. 5. Effect of lead, omega-3 fatty acid (omega-3FA) and their co-treatment on the activity of catalase in brain regions of rats. Values are mean $\pm \mathrm{SE}(n=5)$. ${ }^{*}$ a $p<$ 0.05 -compared to values in the control group, ${ }^{*, \mathrm{~b}} p<0.05$-compared to values in the lead-treated group.

Fig. 6. Effect of lead, omega-3 fatty acid (omega-3FA) and their co-treatment on the activity of glutathione peroxidase in brain regions of rats. Values are mean $\pm \mathrm{SE}$ $(n=5) .{ }^{*}$, a $p<0.05$-compared to values in the control group, ${ }^{*, \mathrm{~b}} p<0.05$-compared to values in the lead-treated group.
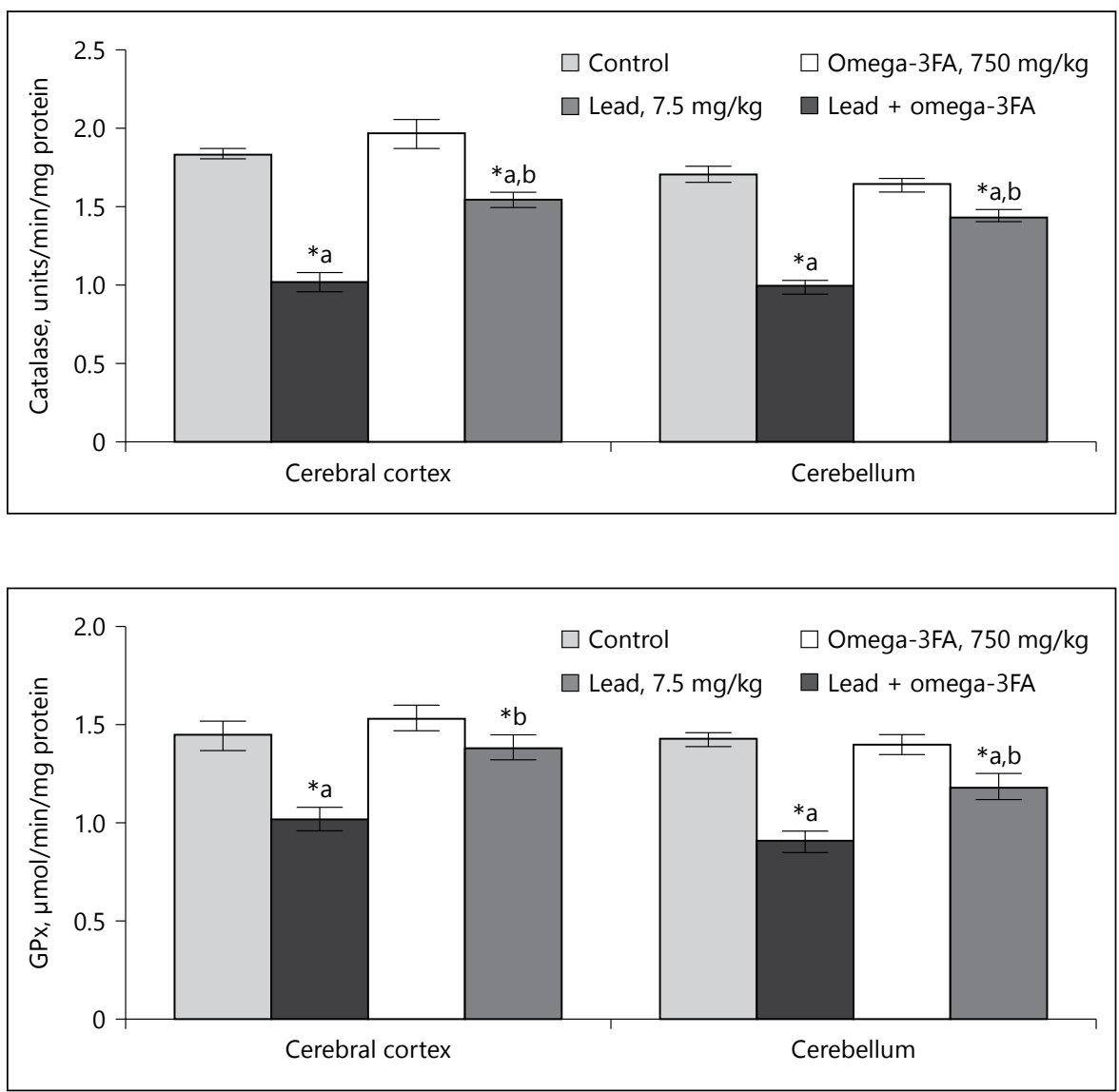

Table 2. Effect of lead, omega-3FA and their co-treatment on lead level in blood and brain regions of rats

\begin{tabular}{lllll}
\hline & Control & Lead $(7.5 \mathrm{mg} / \mathrm{kg})$ & Omega-3FA $(750 \mathrm{mg} / \mathrm{kg})$ & Lead + omega-3FA \\
\hline $\begin{array}{l}\text { Blood Pb level, } \mu \mathrm{g} / \mathrm{dL} \\
\quad \text { Blood }\end{array}$ & $5.56 \pm 1.47$ & $30.28 \pm 1.01^{\mathrm{a}, * * *}$ & $2.88 \pm 0.75$ & $12.02 \pm 1.39^{\mathrm{a}, \mathrm{b}, * *}$ \\
$\begin{array}{l}\text { Brain Pb level, } \mu \mathrm{g} / \mathrm{g} \text { tissue } \\
\quad \text { Cerebral cortex }\end{array}$ & $0.082 \pm 0.008$ & $0.142 \pm 0.0115^{\mathrm{a}, * *}$ & $0.062 \pm 0.0086$ & $0.094 \pm 0.0092^{\mathrm{b}, * *}$ \\
$\quad$ Cerebellum & $0.058 \pm 0.0086$ & $0.104 \pm 0.012^{\mathrm{a}, *}$ & $0.052 \pm 0.0066$ & $0.066 \pm 0.0107^{\mathrm{b}, *}$ \\
\hline
\end{tabular}

All values are mean $\pm \mathrm{SE}(n=5) .{ }^{\mathrm{a}, *} p<0.05 ;{ }^{\mathrm{a}, * *} p<0.01 ;{ }^{\mathrm{a}, * * *} p<0.001$ compared to control group. ${ }^{\mathrm{b}, *} p<0.05 ;{ }^{\mathrm{b}, * *} p<0.01$ compared to lead treated.

(5.4 fold) of rats treated with lead as compared to controls (Table 2). There was a significant decrease in the levels of lead in cerebral cortex ( 1.5 fold), cerebellum (1.6 fold) and in blood ( 2.5 fold) of rats co-treated with lead and omega-3FA as compared to rats treated with lead alone. No significant changes in the level of lead in the brain regions and blood were observed in rats treated with omega-3FA alone as compared to controls (Table 2).

\section{Effect of Lead on Histological Changes of Brain Regions}

Histopathological examination of lead exposure caused neuronal damage in Purkinjee and granular cell layer $(40 \%)$ in cerebellar regions. Co-treatment of rats with lead and omega-3FA reverses the brain damage (42\%) in cerebellar region as compared to rats treated with lead alone (Fig. 7a). White matter showed diffuse oedema characterized by variable-sized fluid-filled spac- 


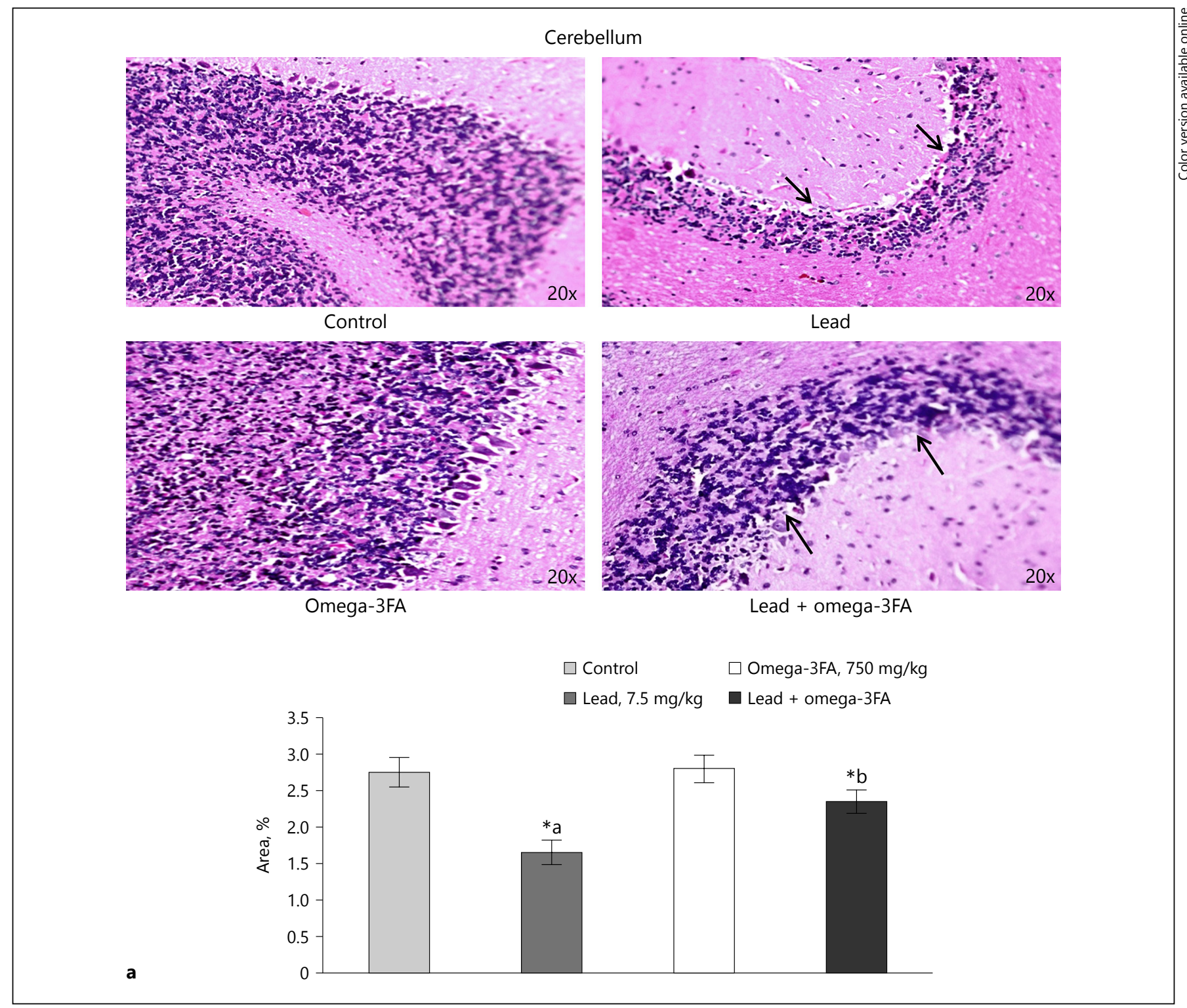

Fig. 7. a Effect of lead, omega-3 fatty acid (omega-3FA) and their co-treatment on cerebellum of rat brain. Control: Showed normal histo-architecture. Lead: showed mild disruption and degenerative changes in Purkinjee and neuronal cell layer. Omega-3FA: showed no significant changes in the histo-architecture. Lead + omega-
3FA: showed the regeneration and protection of Purkinjee and neuronal cell layers. Values are mean $\pm \operatorname{SE}(n=3)$. Significant difference, ${ }^{*}$ a $p<0.05$-compared to values in the control group, ${ }^{*}$, b $p<0.05$-compared to values in the lead-treated group.

\section{Discussion}

A number of studies have revealed that exposure of lead even at low doses is extremely dangerous and results in a variety of neurological disturbances [33, 34]. Epidemiological studies have reported higher frequency of infertility, stillbirths, miscarriages, spontaneous abortion and other neurological disorders in many lead-exposed 


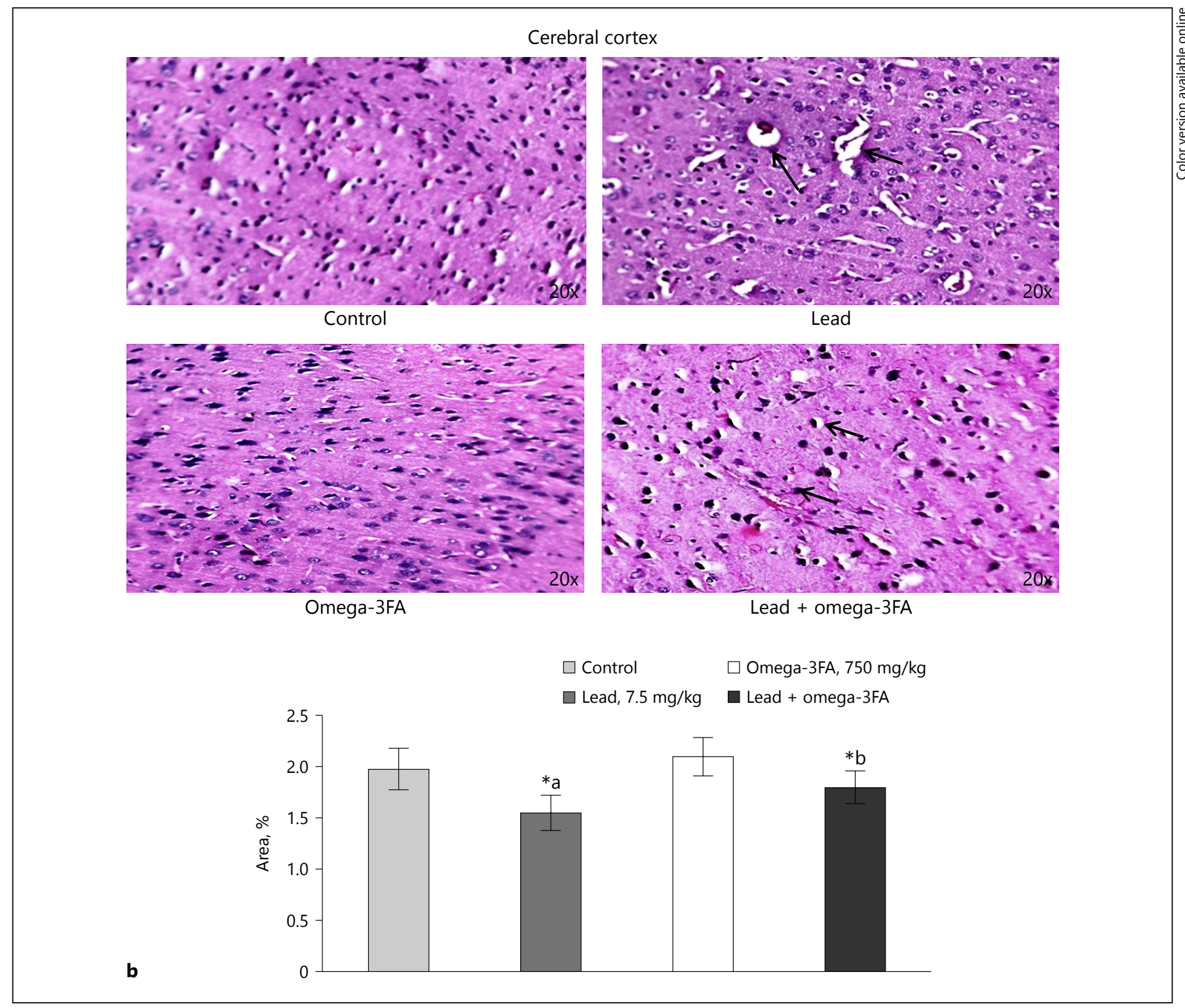

Fig. 7. b Effect of lead, omega-3FA and their co-treatment on cerebral cortex of rat brain. Control: showed normal histo-architecture. Lead: showed mild disruption and degenerative changes in neuronal cells. Omega-3FA: showed resemble no significant changes in the histo-architecture. Lead + omega-3FA: showed the regeneration and protection of neuronal cells in cerebral cortex. Values are mean \pm SE $(n=3)$. Significant difference, ${ }^{*}$, a $p<$ 0.05 -compared to values in the control group, ${ }^{*}$, $p<0.05$-compared to values in the lead-treated group. occupational workers [35]. Exposure of lead to the cell or tissue may cause damage to the nervous system through various mechanisms. It can cross the blood-brain barrier and disrupt the structural components of brain by producing injury to the glial cells, primarily in the cerebral cortex, cerebellum and hippocampus [36]. It is selectively deposited in these brain regions and found to be associated with behavioral abnormalities, learning impairment, decreased hearing, neuromuscular weakness and impaired cognitive functions in humans and in experimental animals [37]. It may also result in many biochemical alterations and a variety of neurological disorders, such as mental retardation, behavioral problems, nerve damage, Alzheimer's disease, schizophrenia and Parkinson's disease $[38,39]$. Studies have also reported the association of lead exposure to CNS damage and cause forgetfulness, 
irritability, poor attention span, headache, fatigue, impotence, dizziness and depression [40]. In the present study, lead exposure was associated with a decrease in body weight when compared to control rats, which was consistent with the previous studies [40]. Exposure to lead may reduce growth and food consumption through the contact of lead with appetite-depressant receptors in the gastrointestinal tract [41]. We have also observed the increased levels of lead in the brain region, which further provides experimental evidence that lead can cause blood-brain barrier and impart its toxic effects. The generation of free radicals associated with the enhanced oxidative stress following exposure to lead has been reported [42]. Experimental studies have shown an increase in lipid peroxidation and impaired antioxidant defence enzymes in brain following lead exposure, suggesting enhanced oxidative stress [43, 44]. Lead exposure is also linked with the depletion of brain GSH contents as indicated by the GSSG/GSSG + GSH ratio [45]. Studies have reported that lead-exposed animals showed a decrease in antioxidant defense mechanisms, such as catalase and superoxide dismutase, suggesting an increase in oxidative stress $[9,46]$. In vitro and in vivo studies have revealed that lead exposure may enhance the generation of ROS and increase the oxidative stress through changes in the antioxidant defense systems in animals [47]. Lead has been found to have high affinity for free-SH groups in enzymes and proteins and hence its binding with these enzymes can alter their efficacy and function. Oxidative stress, induced by disrupting the antioxidant balance in the cells [48], deregulation of cell signalling and neurotransmission alteration have been regarded as potential mechanisms involved in lead-induced neurotoxicity [49]. Earlier, in a long-term exposure study, we have reported that omega-3FA significantly reduced the lead-induced oxidative stress and lead levels in blood and brain associated with brain damage [15]. In the present study, an increase in the level of lipid peroxidation and protein carbonyl contents, decreased levels of SOD and catalase and reduced glutathione clearly indicate the enhanced oxidative stress following lead exposure in rats. The results of the present study were in agreement with the results of previous studies [50].

Studies have been showed that omega-3FA has immunomodulatory, antidiabetic and cardioprotective effects [51]. It could be used for treatment of various diseases including coronary heart disease, cancer and neurological disorders [52]. It also has the ability to cross the bloodbrain barrier and imparts a potent antioxidant role in the CNS [53]. It has a strong antioxidant potential, as it scav-

Attenuation of Lead-Induced

Neurotoxicity by Omega-3FA in Rats enges free reactive oxygen and enhances endogenous antioxidant capabilities [54]. Ross et al. [55] reported the antioxidant activity of omega-3FA, as it reversed the effect of lead toxicity on ROS, protein carbonyl content and MDA levels, which may be attributed due to its high content of omega-3FA. Further, the oil present as main constituents in omega-3FA has an important role in free radical scavenging and singlet oxygen quenching [56]. In humans, the decreased levels of DHA, an important constituent of omega-3FA were found to be associated with neurodegenerative diseases, such as Alzheimer's disease [57], suggesting the beneficial role of DHA to brain health. Studies have been suggested that DHA protected rats against neuronal injury in experimental brain ischemia $[58,59]$ and reduced $\beta$-amyloid cellular damage $[60$, 61 . A number of in vitro and in vivo studies reported that lead exposure might cause the generation of ROS and changes in the antioxidant defence systems in animals and may also occur in human beings $[62,63]$.

Studies have also reported that omega-3FA, DHA and EPA readily enter the brain, most likely by simple diffusion [64] and exhibits a variety of biological activities including strong anti-oxidant, anti-apoptotic, antiinflammatory and neuroprotective activity $[65,66]$. Further supplementation of omega-3FA may preserve phospholipid ratio in the cell membrane by reducing lead toxicity. It is therefore suggested that omega-3FA offers protection against lead neurotoxicity by abovementioned activities and by preventing the accumulation of lead in the brain by eliminating it through urine. The chelating ability of omega-3FA with lead, which has not been clearly understood, but the antioxidant effect could be the possible mechanism of action that might ameliorate the lead-induced enhanced oxidative stress and impart neuroprotection. We have previously reported that omega-3FA is capable of reducing free radical damage either directly acting as a free radical scavenger or indirectly stimulating antioxidant enzyme activities and recovery of brain damage against long-term exposure of lead [15]. In the present study, lead-induced increase in lipid peroxidation and protein carbonyl contents, decreased levels of SOD, catalase and glutathione peroxidase and reduced glutathione have been found to be protected following co-treatment with lead and omega-3FA indicating its neuroprotective efficacy. The increased level of lead in brain and blood has also been found to be decreased in rats co-treated with lead and omega-3FA. A decrease in lead levels in these brain regions could be due to the metal binding and antioxidant properties of omega-3FA.

Ann Neurosci 2017;24:221-232

DOI: $10.1159 / 000481808$ 
Abdel Moniem et al. [67] reported that lead toxicity affects the normal histological structure of the brain and affect the pharmacological and physiological functions performed by them. Further, lead encephalopathy in rat brain has been found to be linked with the cerebral edema, muscular changes and focal cerebellar atrophy involving Purkinje and granular cells and neuronal degeneration [68]. Exposure to lead in rats affects the normal histological structure of the brain and causes disturbances in the normal functions performed by it. Lead toxicity also damages the nerve cells and ganglia linked with the damage of cellular structure as well as the neuronal degeneration as a result of lead encephalopathy in rat brain $[69,70]$.

Studies have shown that lead damages the nerve cells as well as ganglia and also alters the cell structure causing cerebral edema, and focal cerebellar atrophy and neuronal degeneration as a result of lead encephalopathy in rat brain [69]. Treatment with omega-3FA has been found to restore cellular functions, reduce oxidative stress and inflammation, repair cellular damage and mitigate the activation of apoptotic processes after traumatic brain injury in human [71]. Earlier, we have reported that long-term lead exposure produces loss of pigmentation, perinuclear hollow and appearance of diffused oedema in the brain regions and causes alterations in the normal functions performed by them. In the present study, histological damage including neuronal degenerative changes like vacuolation, demyelination, perinuclear hollow and appearance of small shrunken cell in the brain regions have been found to occur due to lead toxicity. The co-treatment with omega-3FA with lead causes a significant decrease in the histopathological changes induced by lead acetate in the brain regions and partially restored these changes as compared to rats treated with lead alone.

\section{Conclusions}

In conclusion, our findings clearly indicate that lead induced oxidative stress and histopathological alterations in rats suggesting that it is one of the hazardous heavy metals. Omega-3FA has been found to ameliorate the lead-induced oxidative stress that could be mediated either directly by scavenging ROS and inhibiting the over production of lipid peroxidation. Further, toxic effects of lead have also been found to be protected by omega-3FA due to its ability to bind with the metal and reduced the load of lead in the body. Omega-3FA supplementation in combination with lead acetate minimizes the effects of

biochemical changes and histopathological alterations caused by lead exposure. There were no significant changes observed in any of the parameters following treatment with omega-3FA alone in rat brain regions.

\section{Acknowledgements}

The authors are thankful to the Head, Department of Pharmacology, King George's Medical University, Lucknow (UP), India for his interest in the study. Dr. Pramod Kumar Singh is grateful to the Indian Council of Medical Research, New Delhi for the award of research fellowship. The technical support by Mr. Shyam Kanaujia is also acknowledged.

\section{Disclosure Statement}

This manuscript complies with ICMJE.

\section{Author Contribution}

P.K.S. contributed in the areas of concepts, design, definition of intellectual content, literature search, experimental studies, data acquisition, data analysis, statistical analysis, manuscript preparation, manuscript editing and manuscript review. M.K.S. contributed in areas of concepts, design, data analysis, statistical analysis, manuscript preparation, manuscript editing and manuscript review. R.S.Y. contributed in design, data analysis, manuscript preparation, manuscript editing and manuscript review. R.K.D. contributed in areas of literature search, experimental studies, data analysis, manuscript preparation, manuscript editing and manuscript review. A.M. contributed in areas of design, definition of intellectual content, manuscript preparation, manuscript editing and manuscript review. R.N. contributed in areas of concepts, design, definition of intellectual content, literature search, experimental studies, data acquisition, data analysis, statistical analysis, manuscript preparation, manuscript editing and manuscript review.

\section{References} therapeutic measures for chronic arsenic and lead poisoning. J Occup Health 2005;47:1-21.

2 Ghareeb DA, Hussien HM, Khalil AA, El-Saadani MA, Ali AN: Toxic effects of lead exposure on the brain of rats: Involvement of oxidative stress, inflammation, acetylcholinesterase, and the beneficial role of flaxseed extract. Toxicol Environ Chem 2009;92:187-195.

3 White LD, et al: New and evolving concepts in the neurotoxicology of lead. Toxicol Appl Pharmacol 2007;225:1-27.

4 Spivey A: The weight of lead. effects add up in adults. Environ Health Perspect 2007;15: A30-A36.

5 Murata K, Iwata T, Dakeishi M, Karita K: Lead toxicity: does the critical level of lead resulting in adverse effects differ between adults and children? J Occup Health 2009;1:1-12. 
6 Lidsky TI, Schneider JS: Adverse effects of childhood lead poisoning: The clinical neuropsychological perspective. Environ Res 2006; 100:284-293.

7 Menke A, Muntner P, Batuman P, Silbergeld EK, Guallar E: Blood lead below 0.48 micromol/L (10 microgL) and mortality among US adults. Circulation 2006;114: 1388-1394.

8 Shukla PK, Khanna VK, Khan MY, Srimal RC: Protective effect of curcumin against lead neurotoxicity in rat. Hum Exp Toxicol 2003; 12:653-658

9 Hossain S, Bhowmick S, Jahan S, Rozario L, Sarkar M, Islam S, Basunia MA, Rahman A, Choudhury BK, Shahjalal H: Maternal lead exposure decreases the levels of brain development and cognition-related proteins with concomitant upsurges of oxidative stress, inflammatory response and apoptosis in the offspring rats. Neurotoxicol 2016;56:150-158.

10 Cleveland LM, Minter ML, Cobb KA, Scott AA, German VF: Lead hazards for pregnant women and children: part 1: immigrants and the poor shoulder most of the burden of lead exposure in this country. Part 1 of a two-part article details how exposure happens, whom it affects, and the harm it can do. Am J Nurs 2008;108:40-49.

11 Goyer RA: Results of lead research: prenatal exposure and neurological consequences. Environ Health Perspect 1996;104:1050-1054.

12 Kasperczyk S, Birkner E, Kasperczyk A, Kasperczyk J: Lipids, lipid peroxidation and 7-ketocholesterol in workers exposed to lead. Hum Exp Toxicol 2005;24:287-295.

13 Flora SJ: Nutritional components modify metal absorption, toxic response and chelation therapy. J Nut Environ Med 2002;12:5367.

14 Sanders T, Liu Y, Buchner V, Tchounwou PB: Neurotoxic effects and biomarkers of lead exposure: a review. Res Environ Health 2009;24: $15-45$.

15 Singh PK, Nath R, Ahmad KM, Rawat A, Babu S, Dixit RK: Attenuation of lead neurotoxicity by supplementation of polyunsaturated fatty acid in Wistar rats. Nutr Neurosci 2016;19:396-405.

16 Singh PK, Rawat A, Dixit RK, Kumar P, Nath R: Behavioral and neurochemical effects of omega-3 fatty acids against lead aetate exposure in male wistar rats: an experimental study. Int J Curr Res 2015;7:20936-20944.

17 Denis I, Potier B, Heberden C, Vancasse S: Omega-3 polyunsaturated fatty acids and brain aging. Curr Opin Clin Nutr Metab Care 2015;18:139-146.

18 Parletta N, Milte CM, Meyer BJ: Nutritional modulation of cognitive function and mental health. J Nutr Biochem 2013;24:725-743.

19 Wainwright PE: Dietary essential fatty acids and brain function: a developmental perspective on mechanisms. Proc Nutr Soc 2002;61: 61-69.

20 Feng Z, Zou X, Jia H, Li X, Zhu Z, Liu X, Bucheli P, Ballevre O, Hou Y, Zhang W, Wang J,
Chen Y, Liu J: Maternal docosahexaenoic acid feeding protects against impairment of learning and memory and oxidative stress in prenatally stressed rats: possible role of neuronal mitochondria metabolism. Antioxid Redox Signal 2012;16:275-289.

21 Tuzun F, Kumral A, Ozbal S, Dilek M, Tugyan K, Duman N, Ozkan H: Maternal prenatal omega-3 fatty acid supplementation attenuates hyperoxia-induced apoptosis in the developing rat brain. Int J Dev Neurosci 2012; 30:315-323.

$22 \mathrm{Wu}$ A, Ying Z, Gomez-Pinilla F: Docosahexaenoic acid dietary supplementation enhances the effects of exercise on synaptic plasticity and cognition. Neurosci 2008;155:751759.

23 Rathod R, Kale A, Joshi S: Novel insights into the effect of vitamin $B_{12}$ and omega- 3 fatty acids on brain function. J Biomed Sci 2016;23: 17.

24 Glowinski J, Iversen LL: Regional studies of catecholamines in the rat brain. I. The disposition of $[3 \mathrm{H}]$ norepinephrine, $[3 \mathrm{H}]$ dopamine and $[3 \mathrm{H}]$ dopa in various regions of the brain. J Neurochem 1966;13:655-659.

25 Socci DJ, Bjugstad KB, Jones HC, Pattisapu JV, Arendash GW: Evidence that oxidative stress is associated with the pathophysiology of inherited hydrocephalus in the H-Tx rat model. Exp Neurol 1999;155:109-117.

26 Ohkawa H, Ohishi N, Yagi K: Assay for lipid peroxides in animal tissues by thiobarbituric acid reaction. Anal Biochem 1979;95:51-58.

27 Levine RL, Garland D, Oliver CN, Amici A, Climent I, Lenz AG, Ahn BW, Shaltiel S, Stadtman ER: Determination of carbonyl content in oxidatively modified proteins. Methods Enzymol 1990;186:464-478.

28 McCord JM, Fridovich I: Superoxide dismutase. An enzyme function for erythrocuprin (hemocuprin). J Biol Chem 1969;224: 6049-6055.

29 Aebi H: Catalase in vitro. Enzymol 1984;105: 121-126.

30 Pagila DE, Valentine WN: Studies on the quantitation and qualitation characterization of erythrocyte glutathione peroxidase. J Lab Clin Med 1967;70:158-169.

31 Lowry OH, Rosebrough NJ, Farr AL, Randall R: Protein measurement with the Folin phenol reagent. J Biol Chem 1951;193:265275.

32 Gupta V, Gill KD: Influence of ethanol on lead distribution and biochemical changes in rats exposed to lead. Alcohol 2000;20:9-17.

33 Mazumdar M, Bellinger DC, Gregas M, Abanilla K, Bacic J, Needleman HL: Low-level environmental lead exposure in childhood and adult intellectual function: a follow-up study. Environ Health 2011;10:24.

34 Shelton JF, Geraghty EM, Tancredi DJ, Delwiche LD, Schmidt RJ, Ritz B: Neurodevelopmental disorders and prenatal residential proximity to agricultural pesticides: the CHARGE study. Environ Health Perspect 2014;122:1103-1109.
35 Henn SA, Sussell AL, Li J, Shire JD, Alarcon WA, Tak S: Characterization of lead in US workplaces using data from OSHA's integrated management information system. Am J Ind Med 2011;54:356-365.

36 Gandhi S, Abramov AY: Mechanism of oxidative stress in neurodegeneration. Oxidat Med Cell Longev 2012;2012:11

37 Verina T, Rohde CA, Guilarte TR: Environmental lead exposure during early life alters granule cell neurogenesis and morphology in the hippocampus of young adult rats. Neurosci 2007;145:1037-1047.

38 Bazrgar M, GoudarziI, Lashkarbolouki $\mathrm{T}$, Salmani ME: Melatonin ameliorates oxidative damage induced by maternal lead exposure in rat pups. Physiol Behav 2015;151:178-188.

39 Jaya Prasanthi RP, Hariprasad RG, Bhuvaneswari DC, Rajarami RG: Zinc and calcium reduce lead induced perturbations in the aminergic system of the developing brain. Biometals 2005; 18:615-626.

40 Yun HJ, Kim I, Kwon S, Kang J, Om A: Protective effects of chlorella vulgaris against lead- induced oxidative stress in rat brains. J Health Sci 2011;57):245-254.

41 Hammond PB, Chernausek SD, Succop PA, Shukla R, Bornschein RL: Mechanisms by which lead depresses linear and ponderal growth in weanling rats. Toxicol Appl Pharmacol 1989;99:474-486.

42 Soltaninejad K, Kebriaeezadeh A, Minaiee B, Ostad SN, Hosseini R, Azizi E, Abdollahi M: Biochemical and ultrastructural evidences for toxicity of lead through free radicals in rat brain. Hum ExpToxicol 2003;22:417-423.

43 Sharma S, Sharma V, Paliwal RP: Lead toxicity, oxidative damage and health implications. Int J Biotechnol Mol Biol Res 2011;2:215-221.

44 Velaga MK, Basuri CK, Taylor KSR, Yallapragada PR, Rajanna S and Rajanna B: The ameliorative effect of Bacopa monniera on lead induced oxidative stress in different region of rat brain. Drug Chem Toxicol 2014; 37:357-364.

45 Adegbesan BO, Adenuga GA: Effect of lead exposure on liver lipid peroxidative and antioxidant defense systems of protein-undernourished rats. Biol Trace Elem Res 2007;116: 219-225.

46 Flora SJ, Saxena G, Mehta A: Reversal of leadinduced neuronal apoptosis by chelation treatment in rats: role of ROS and intracellular $\mathrm{Ca}(+2)$. J Pharmacol Exp Ther 2007;322: 108-116.

47 Flora G, Gupta D, Tiwari A: Toxicity of lead: a review with recent updates. Interdiscip Toxicol 2012;5:47-58.

48 Bokara KK, Brown E, McCormick R, Yallapragada PR, Rajanna S, Bettaiya R: Lead-induced increase in antioxidant enzymes and lipid peroxidation products in developing rat brain. Biometals 2008;21:9-16.

49 Li X, Ye F, Li L, Chang W, Wu X, Chen J: The role of HO-1 in protection against lead-induced neurotoxicity. Neurotoxicol 2016;52: $1-11$. 
50 Abdel-Wahab BA, Metwally ME: Protective effect of alpha lipoic acid against lead induced hippocampal neurotoxicity and neuronal oxidative stress in rats. Austin J Pharmacol Ther 2014;2:8.

51 Sekine S, Sasanuki S, Murana Y, Aoyama T, Takeuchi H: Alphalinolenic acid-rich flaxseed oil ingestion increases plasma adiponectin level in rats. Int J Vitam Nutr Res 2008;78: 223-229.

52 Simopoulos AP: The importance of the ratio of omega-6/omega-3 essential fatty acids. Biomed Pharmacother 2002;56:365-379.

53 Dixit S, Dhar P, Mehra RD: Alpha lipoic acid (ALA) modulates expression of apoptosis-associated proteins in hippocampus of rats exposed during postnatal period to sodium arsenite $\left(\mathrm{NaAsO}_{2}\right)$. Toxicol Rep 2015;2:78-87.

54 Attia AM, El-Banna, SG, Nomeir FR, ElBasser MI: Lindane-induced biochemical perturbations in rat serum and attenuation by omega-3 and Nigella sativaseed oil. Indian J Biochem Biophys 2011;48:184-190.

55 Ross SR, Lexin W, Herbert J: Erythrocyte oxidative damage in chronic fatigue syndrome. Arch Med Res 2007;38:94-98.

56 Bhatia AL, Sharma A, Patni S, Sharma AL: Prophylactic effect of flaxseed oil against radiation-induced hepatotoxicity in mice. Phytother Res 2007;21:852-885.

57 Schaefer EJ, Bongard V, Beiser AS, LamonFava S, Robins JS, Au R, Tucker KL, Kyle DJ, Wilson PW, Wolf PA: Plasma phosphatidylcholine docosahexaenoic acid content and risk of dementia and Alzheimer disease: the Framingham Heart Study. Arch Neurol 2006; 63:1545-1550.

58 Bas O, Songur A, Sahin O, Mollaoglu H, Ozen OA, Yaman M, Eser O, Fidan H, Yagmurca $\mathrm{M}$ : The protective effect of fish oil n-3 fatty acids on cerebral ischemia in rat hippocampus. Neurochem Int 2007;50:548-554

59 Belayev L, Marchezelli VL, Khoutorova L, Rodriguez de Turco EB, Busto R, Ginsberg MD, Bazan NG: Docosahexaenoic acid complexed to albumin elicits high-grade ischemic neuroprotection. Stroke 2005;36:118-123.

60 Florent S, Malaplate-Armand C, Youssef I, Kriem B, Koziel V, Escanyé MC, Fifre A, Sponne I, Leininger-Muller B, Olivier JL, Pillot T, Oster T: Docosahexaenoic acid prevents neuronal apoptosis induced by soluble amyloid-beta oligomers. J Neurochem 2006;96: 385-395.

61 Lukiw WJ, Cui JG, Marcheselli VL, Bodker M, Botkjear A, Gotlinger K, Serhan CN, Bazan NG: A role for docosahexaenoic acid-derived neuroprotectin D1 in neural cell survival and Alzheimer disease. J Clin Invest 2005;115: 2774-2783.

62 Flora G, Gupta D, Tiwari A: Toxicity of lead: a review with recent updates. Inter discip Toxicol 2012;5:47-58.

63 Su P, Zhang J, Wang S, Aschner M, Cao Z, Zhao F, Wang D, Chen J, Luo W: Genistein alleviates lead-induced neurotoxicity in vitro and in vivo: Involvement of multiple signaling pathways. Neurotoxicol. 2016;53:153-164.
64 Ouellet M, Emond V, Chen CT, Julien C, Bourasset F, Oddo S: Diffusion of docosahexaenoic and eicosapentaenoic acids through the blood-brain barrier: an in situ cerebral perfusion study. Neurochem Int 2009; 55:476-482.

65 Calviello G, Serini S: Dietary Omega-3 Polyunsaturated Fatty Acids and Cancer. London, Diet and Cancer, 2010.

66 Calder PC: Polyunsaturated fatty acids and inflammatory processes: new twists in an old tale. Biochimie 2009;91:791-795.

67 Abdel Moniem AE, Dkhil MA, Al-Quraishy $S$ : Effects of flaxseed oil on lead acetate-induced neurotoxicity in rats. Biol Trace Elem Res 2011;144:904-913.

68 Clasen RA, Hartmann JF, Coogan PS, Pandolfi S, Laing I, Becker RA: Experimental acute lead encephalopathy in the juvenile rhesus monkey. Environ Health Perspect 1974;7: 175-185.

69 Sidhu P, Nehru B: Lead intoxication: histological and oxidative damage in rat cerebrum and cerebellum. J Trace Elem Exp Med 2004; 17:45-53.

70 Ghazwan A, Raouf M, Kumar V: Terminalia arjuna bark extract inhibits histological alterations by mitigating oxidative stress in lead intoxicated mice. Orient Pharm Exp Med 2013;13:253-265.

71 Hasadsri L, Wang BH, Lee JV, Erdman JW, Llano DA, Barney AK: Omega-3 fatty acids as a putative treatment for traumatic brain injury. J Neurotrauma 2013;30:897-906. 